\title{
Psychosocial findings in alcohol-dependent patients before and after three months of total alcohol abstinence
}

\section{Anna Ferrulli' , Lorenzo Leggio ${ }^{1,2 *}$, Silvia Cardone ${ }^{1}$, Cristina D'Angelo ${ }^{1}$, Antonio Mirijello', Luisa Vonghia', Antonio Miceli ${ }^{3,4}$, Giovanni Gasbarrini' ${ }^{1}$ and Giovanni Addolorato ${ }^{1 *}$}

\author{
Institute of Internal Medicine, Catholic University of Rome, Rome, Italy \\ 2 Center for Alcohol and Addiction Studies, Brown University, Providence, RI, USA \\ 3 Fondazione G. Monasterio CNR-Regione Toscana, Massa, Italy \\ ${ }^{4}$ Bristol Heart Institute, University of Bristol, Bristol, UK
}

Edited by:

Lara Ray, University of California, Los Angeles, USA

\section{Reviewed by:}

Fabio Caputo, Department of Internal Medicine, Italy; Hospital of Ferrara, Italy

Otto Lesch, Medical University of Vienna, Austria

*Correspondence:

Lorenzo Leggio, Institute of Internal Medicine, Catholic University of Rome, Rome 00168, Italy; Center for Alcohol and Addiction Studies, Brown University, Providence, RI 02903, USA. e-mail: lorenzo_leggio@brown.edu; Giovanni Addolorato, Institute of Internal Medicine, Catholic University of Rome, Rome 00168, Italy. e-mail: g.addolorato@rm.unicatt.it
Alcohol use disorders (AUDs) may be associated with several psychological and affective disorders. It is controversial, however, if these symptoms are a cause or rather a consequence of alcohol dependence. There are few data testing simultaneously psychosocial and affective disorders before and after a period of alcohol abstinence. The aim of this study was to perform multiple psychometric evaluations in alcohol-dependent patients before and after 12 weeks of abstinence. Twenty-five alcohol-dependent patients were included in the study. The following psychometric tests were administered at baseline (T0) and after 12 weeks (T1): addiction severity index (ASI), brief psychiatric rating scale (BPRS), social behavior scale (SBS), Sheehan disability scale (DISS), aggression questionnaire (AQ). At T1, 16 (64\%) patients were abstinent, 5 (20\%) patients dropped out and 4 (16\%) patients relapsed. Compared toT0, patients totally abstinent at T1 showed a significant reduction of the scores related to BPRS, BPRS-E and its subscales (except BPRS 5), ASI 1, ASI 2, ASI 3, ASI 6, ASI 7, BSM, AQ, DISS 1, DISS 2, DISS $3(p<0.05)$. No significant changes in ASI 4, ASI 5, DISS 4, and DISS 5, BPRS 5 scores were found at T1 compared to T0. The present study indicates that total alcohol abstinence improves psychometric features, such as alcohol addiction severity, psychiatric rating, social behavior, aggressiveness, and disability. Larger controlled studies are needed to confirm these findings.

Keywords: alcohol dependence, alcohol addiction severity, social behavior, aggressiveness, disability

\section{INTRODUCTION}

Alcohol use disorders (AUDs) may be associated with several psychological and affective disorders (Ross et al., 1988; Marshall and Alam, 1997). Among them, depression, anxiety, and anti-social personality disorders have been reported in alcoholics (ModestoLowe and Kranzler, 1999). Moreover, several studies demonstrated that AUDs facilitate impulsive (Dom et al., 2006) and aggressive behaviors (Giancola, 2002). However, it is still controversial if psychological and affective symptoms may be a cause or rather a consequence of alcohol dependence (Schuckit, 2006). In fact, affective disturbances may precede the development of alcoholism ("initial" affective disturbances) or, more often, they may be "secondary" to several years of alcohol abuse (Bokij, 1983; Schuckit and Monteiro, 1988). For example, subjects with a history of alcohol abuse and/ or alcohol dependence may develop affective disorders, which can mimic a depressive episode (Mayfield and Coleman, 1968) or an anxious mood (Stockwell and Bolderston, 1987).

Although several affective disorders can be simultaneously present in alcohol-dependent individual, there are few data available testing in the same time several of these disorders, such as aggression, impulsivity, negative symptoms, activation problems solving, social interaction, and their relationship before and after a period of alcohol abstinence. The identification of these psychological and affective disorders in alcoholic patients is of importance because they may have clinical and prognostic implications, such as psychosocial problems, non-compliance to pharmacological treatments, risk of alcohol relapse (Kranzler et al., 1998). On the other hand, these psychological and affective disorders may improve and even recovery after persistent alcohol abstinence (Kranzler, 1996).

In the present study, we performed several psychometric assessments in patients affected by alcohol dependence and without any other psychiatric diagnosis according to the DSM-IV. Aim of this study was to perform multiple psychometric assessments in alcohol-dependent patients both before and after 12 weeks of total alcohol abstinence.

\section{MATERIALS AND METHODS PATIENTS}

Data were obtained from a sample of alcohol-dependent subjects previously described (Leggio et al., 2008a,b). Briefly, 80 alcohol-dependent patients according to the DSM-IV (American Psychiatric Association, 1994) and referred to our Alcoholism Treatment Unit (Institute of Internal Medicine; Catholic University, Rome, Italy) were evaluated after giving their written informed consent. The protocol complied fully with the guidelines of the Ethics Committee of the Catholic University of Rome and with the Helsinki Declaration of 1975, as revised in 1983.

Patients considered for further analysis were active drinkers with an alcohol intake over $80 \mathrm{~g}$ of ethanol/day during the $24 \mathrm{~h}$ before the admission day (baseline: T0). The following exclusion criteria were 
applied: a current axis-I psychiatric diagnosis on DSM-IV other than alcohol or nicotine dependence, a current axis-II psychiatric disorder according to the DSM-IV, a history in the last 6 months of substance abuse or dependence (excluding alcohol or nicotine), alcohol withdrawal syndrome requiring a pharmacological treatment, alcoholic hallucinosis, epilepsy, low intelligence quotient (IQ < 70), amnesic disorders, obesity, endocrine disorders, hypoalbuminemia, severe liver, pancreatic, kidney, and/or cardiovascular impairment, neoplastic diseases, pregnancy, lactating, taking medications potentially influencing metabolism, endocrine system and/or craving, major surgery.

Twenty-five active drinking alcohol-dependent patients [18 (72\%) males; 7 (28\%) females] satisfying the inclusion/exclusion criteria were considered at baseline. Age, gender, occupation, daily alcohol intake, and mean duration of alcohol dependence are reported in Table 1. At the time of the enrolment, patients were abstinent from alcohol for a period ranging between 3 up to 14 days. These 25 patients were included in a multidisciplinary treatment program to achieve and maintain abstinence from alcohol, by means of psychological support counseling and self-help groups, and baclofen administration (10 $\mathrm{mg}$ three times/day orally administered). Baclofen was chosen as the drug treatment based on previous research by our laboratory (Addolorato et al., 2002, 2007). During these 12 weeks of treatment, no other medications were administered.

Patients were checked as outpatients every 2 weeks. Methods to evaluate alcohol abstinence were patient's self-reported alcohol intake (as the mean number of standard drinks consumed per day), family member interview, determination of blood alcohol concentration (BAC), and laboratory tests [aspartate aminotransferase (AST), alanine aminotransferase (ALT), gamma glutamyltranspeptidase $(\gamma$-GT) and mean cellular volume (MCV)].

Of the 25 patients initially enrolled in the study, at 12 weeks (T1) five patients (20\%) dropped out and four patients (16\%) relapsed.

\section{METHODS}

The following psychometric assessments were performed in our sample on the day of admission (T0) and after 12 weeks (T1) (see also Table 2).

\section{Addiction severity index (ASI)}

The ASI is a semi-structured interview that investigates seven domains [medical (ASI 1), employment (ASI 2), alcohol (ASI 3), drugs (ASI 4), family and social (ASI 5), legal (ASI 6), and psychiatric
(ASI 7)] in which individuals with substance use disorders typically have problems (McLellan et al., 1980; Hodgins and el-Guebaly, 1992). For each of the seven domains, there is a severity rating ranging from 0 ("no problems/no need for help") to 9 ("extreme problems/extreme need for help"). The ASI has gained widespread use as a measure of functional status of alcohol-dependent patients both before and after treatment programs (Dritschel and Pettinati, 1989; Alterman et al., 1990; Langeland et al., 2003; Batki et al., 2007), exploiting the advantage of a multidimensional approach to addictive problems.

\section{Brief psychiatric rating scale (BPRS) and expanded BPRS (BPRS-E)}

The BPRS investigates five psychopathological domains: (1) affective, mood and anxiety-related disorders; (2) negative symptoms; (3) psychotic and thinking disorders; (4) activation; and (5) hostility and suspiciousness. In particular, we used both the 18-item BPRS version originally developed by Overall and Gorham (1962) and the 24-item BPRS-E version developed by Ventura et al. (1993). Several studies have used the BPRS to assess the psychopathological state of alcohol-dependent patients (Miller et al., 1986; Driessen et al., 2008; Martinotti et al., 2008).

\section{Social behavior scale (SBS)}

The SBS is a semi-structured interview that investigates 21 areas of social disablement and difficulties. In particular, the SBS is able to identify social behaviors in psychiatric patients, including those with addictive disorders (Wykes and Sturt, 1986). For each of the 21 items, there is a score rating from 0 ("no problem or acceptable behavior") to 4 ("serious problem"). A further score can be derived considering the sum of all items scoring from 2 to 4 (Wykes and Sturt, 1986). This score targets the mild and severe problems score (BSM). We used the BSM score for the present study, as previously described by Hamid et al. (1995).

\section{Sheehan disability scale (DISS)}

The DISS is an analogic self-reported scale, which uses visual-spatial, numeric, and verbal descriptive anchors to assess disability across five domains, namely work (DISS 1), social life (DISS 2), family life (DISS 3), perceived stress (DISS 4), and social support (DISS 5). The DISS represents a simple, cost-effective, and sensitive assessment to measure disability and functional impairment in psychiatric disorders (Sheehan et al., 1996; Carpiniello et al., 2002; Troisi et al., 2007).

Table 1 | Baseline socio-demographic and alcohol drinking characteristics in the group of 25 patients, in the 16 patients totally abstinent after 12 weeks and in the nine patients that were not abstinent during the 12-week period or dropped out.

\begin{tabular}{|c|c|c|c|}
\hline & $\begin{array}{l}\text { Baseline group of } \\
\text { patients }(n=25) \text { at } \\
\text { baseline (TO) }\end{array}$ & $\begin{array}{l}\text { Patients totally abstinent } \\
\text { (after } 12 \text { weeks; } n=16 \text { ) at } \\
\text { baseline (TO) }\end{array}$ & $\begin{array}{l}\text { Patients not abstinent or } \\
\text { dropped out (after } 12 \text { weeks; } \\
n=9 \text { ) at baseline (TO) }\end{array}$ \\
\hline Age (years) & $42.9 \pm 9.4$ & $46.3 \pm 6.3$ & $36.9 \pm 11.3^{\dagger}$ \\
\hline Gender (M/F) & $18 / 7$ & $10 / 6$ & $8 / 1$ \\
\hline Employed, $n(\%)$ & 56 & 62.5 & 44.4 \\
\hline Daily alcohol intake (g) & $237.9 \pm 92.6$ & $228.8 \pm 84.1$ & $256.3 \pm 111.6$ \\
\hline Mean duration of alcohol dependence (years) & $10.9 \pm 7.5$ & $13 \pm 8$ & $7.1 \pm 4.9$ \\
\hline
\end{tabular}

${ }^{t} p<0.05$ vs. the group of 16 patients. 
Table 2 | Psychometric tests and their explored domains.

\begin{tabular}{|c|c|c|}
\hline & Psychometric tests & Explored domains \\
\hline ASI 1 & Addiction Severity Index 1 & Medical status \\
\hline ASI 2 & Addiction Severity Index 2 & Employment status \\
\hline ASI 3 & Addiction Severity Index 3 & Alcohol use \\
\hline ASI 4 & Addiction Severity Index 4 & Drug use \\
\hline ASI 5 & Addiction Severity Index 5 & Legal status \\
\hline ASI 6 & Addiction Severity Index 6 & Family/social relations \\
\hline ASI 7 & Addiction Severity Index 7 & Psychiatric status \\
\hline 18-item & 18-item Brief Psychiatric & General \\
\hline BPRS & Rating Scale & psychopathological status \\
\hline E-BPRS & $\begin{array}{l}\text { Expanded Brief Psychiatric } \\
\text { Rating Scale }\end{array}$ & $\begin{array}{l}\text { General } \\
\text { psychopathological status }\end{array}$ \\
\hline BPRS 1 & $\begin{array}{l}\text { Brief Psychiatric Rating } \\
\text { Scale } 1\end{array}$ & $\begin{array}{l}\text { Affective, mood and } \\
\text { anxiety-related disorders }\end{array}$ \\
\hline BPRS 2 & $\begin{array}{l}\text { Brief Psychiatric Rating } \\
\text { Scale } 2\end{array}$ & Negative symptoms \\
\hline BPRS 3 & $\begin{array}{l}\text { Brief Psychiatric Rating } \\
\text { Scale } 3\end{array}$ & $\begin{array}{l}\text { Psychotic and thinking } \\
\text { disorders }\end{array}$ \\
\hline BPRS 4 & $\begin{array}{l}\text { Brief Psychiatric Rating } \\
\text { Scale } 4\end{array}$ & Activation symptoms \\
\hline BPRS 5 & $\begin{array}{l}\text { Brief Psychiatric Rating } \\
\text { Scale } 5\end{array}$ & $\begin{array}{l}\text { Hostility and } \\
\text { suspiciousness }\end{array}$ \\
\hline $\begin{array}{l}\text { SBS in } \\
\text { the form } \\
\text { of BSM }\end{array}$ & Social Behavior Scale & $\begin{array}{l}\text { Social disablement and } \\
\text { difficulties evaluated in } \\
\text { the form of BSM which } \\
\text { targets the mild and } \\
\text { severe problems score }\end{array}$ \\
\hline DISS 1 & Sheehan Disability Scale 1 & Work status \\
\hline DISS 2 & Sheehan Disability Scale 2 & Social life status \\
\hline DISS 3 & Sheehan Disability Scale 3 & Family life status \\
\hline DISS 4 & Sheehan Disability Scale 4 & Perceived stress \\
\hline DISS 5 & Sheehan Disability Scale 5 & Social and family support \\
\hline $\mathrm{AO}$ & Aggression Questionnaire & $\begin{array}{l}\text { Physical aggression, } \\
\text { verbal aggression, anger } \\
\text { and hostility }\end{array}$ \\
\hline
\end{tabular}

\section{Aggression questionnaire (AQ)}

The AQ is a 29-item self-administered scale, which assesses four dimensions of aggression, namely physical aggression, verbal aggression, anger, and hostility (Buss and Perry, 1992). The AQ is the most widely used instrument for the assessment of aggressive behaviors (Gerevich et al., 2007). Recently, the AQ has been used to assess aggressive behaviors in alcoholic patients (Gerevich et al., 2007; Bácskai et al., 2009).

\section{STATISTICAL ANALYSIS}

In this research, the analysis was performed considering: (1) at baseline, the 25 patients initially enrolled; (2) both at baseline and at 12 weeks, the 16 patients totally abstinent after 12 weeks; and (3) at baseline, the 9 patients that were not abstinent during the 12-week period or dropped out before the end of the study. Furthermore, the analysis of the psychometric assessments included: (1) the changes of all the scores and subscores at T1 compared to T0; (2) the relationships between all the assessment scores at T0; and (3) the relationships between all the assessment scores at $\mathrm{T} 1$.

Values were expressed as mean \pm SD and categorical data as percentages. The normality of data distribution was tested by the Kolmogorov-Smirnov test and when abnormal, the data were log transformed. Pearson correlation coefficients were used to test the correlations among data analyzed. The paired sample $t$-test was used to compare subjects at $\mathrm{T} 0$ and $\mathrm{T} 1$. The a priori limit for statistical significance was $p<0.05$.

\section{RESULTS}

\section{CHANGES OF THE PSYCHOMETRIC ASSESSMENTS FROM BASELINE (TO) TO 12-WEEK (T1)}

Table 3 reports all the scores expressed as mean \pm SD of all the psychometric assessments (ASI, BPRS, BSM, DISS, AQ) performed in our alcohol-dependent patients at T0 and T1. There was a significant improvement of several psychometric assessments at T1 compared to T0. In particular, there was a significant reduction of the scores related to BPRS, BPRS-E and its subscales (except BPRS 5), ASI 1, ASI 2, ASI 3, ASI 6, ASI 7, BSM, AQ, DISS 1, DISS 2 , DISS $3(p<0.05)$. No significant changes of ASI 4 , ASI 5 , DISS 4 , and DISS 5, BPRS 5, scores were found at T1 compared to T0 $(p>0.05)$.

\section{RELATIONSHIPS BETWEEN THE PSYCHOMETRIC ASSESSMENTS AT BASELINE (TO)}

In the 25 alcohol-dependent patients initially enrolled at $\mathrm{T} 0$, the following statistically significant correlations were found (see also Figure 1). Both BPRS and BPRS-E showed a positive significant correlation with ASI 3 (respectively: $r=0.62, p=0.001$; $r=0.62, p=0.001$ ), ASI 7 (respectively: $r=0.66, p<0.001$; $r=0.64, p=0.001$ ), BSM (respectively: $r=0.86, p<0.001 ; r=0.87$, $p<0.001$ ), AQ (respectively: $r=0.46, p=0.02 ; r=0.40, p=0.045$ ), DISS 1 (respectively: $r=0.48, p=0.015 ; r=0.49, p=0.013$ ), DISS 2 (respectively: $r=0.64, p=0.001 ; r=0.62, p=0.001$ ), and DISS 3 (respectively: $r=0.57, p=0.003 ; r=0.53, p=0.006$ ). Both ASI 3 and ASI 7 positively correlated with BSM (respectively: $r=0.64$, $p=0.001 ; r=0.59, p=0.002$ ). Both ASI 6 and ASI 7 positively correlated with AQ (respectively: $r=0.58, p=0.002 ; r=0.43$, $p=0.031)$. Both ASI 3 and ASI 6 positively correlated with the first four DISS scores, specifically DISS 1 (respectively: $r=0.45$, $p=0.025 ; r=0.52, p=0.008$ ), DISS 2 (respectively: $r=0.49$, $p=0.011 ; r=0.39, p=0.049$ ), DISS 3 (respectively: $r=0.47$, $p=0.018 ; r=0.51, p=0.009$ ), and DISS 4 (respectively: $r=0.39$, $p=0.048 ; r=0.69, p<0.001)$. ASI 7 positively correlated with DISS $2(r=0.49, p=0.012)$. Finally, BSM positively correlated with DISS $2(r=0.56, p=0.004)$ and DISS $3(r=0.45, p=0.022)$.

At T0, we also analyzed all the relationships among the psychometric assessments in the subgroup of 16 subjects that were totally abstinent after 12 weeks (see also Figure 2). We found the same significant correlations reported above for the whole group of 25 patients (data not shown) with only the following differences: (1) AQ did not correlated with BPRS nor with BPRS-E $(p>0.05)$; and (2) AQ did not correlate with ASI 6 nor with ASI 7 ( $p>0.05)$. 
Table 3 | Psychometric tests in the baseline group of 25 patients, in the 16 patients totally abstinent after 12 weeks (both at baseline and at 12 weeks) and in the nine patients that were not abstinent during the 12-week period or dropped out.

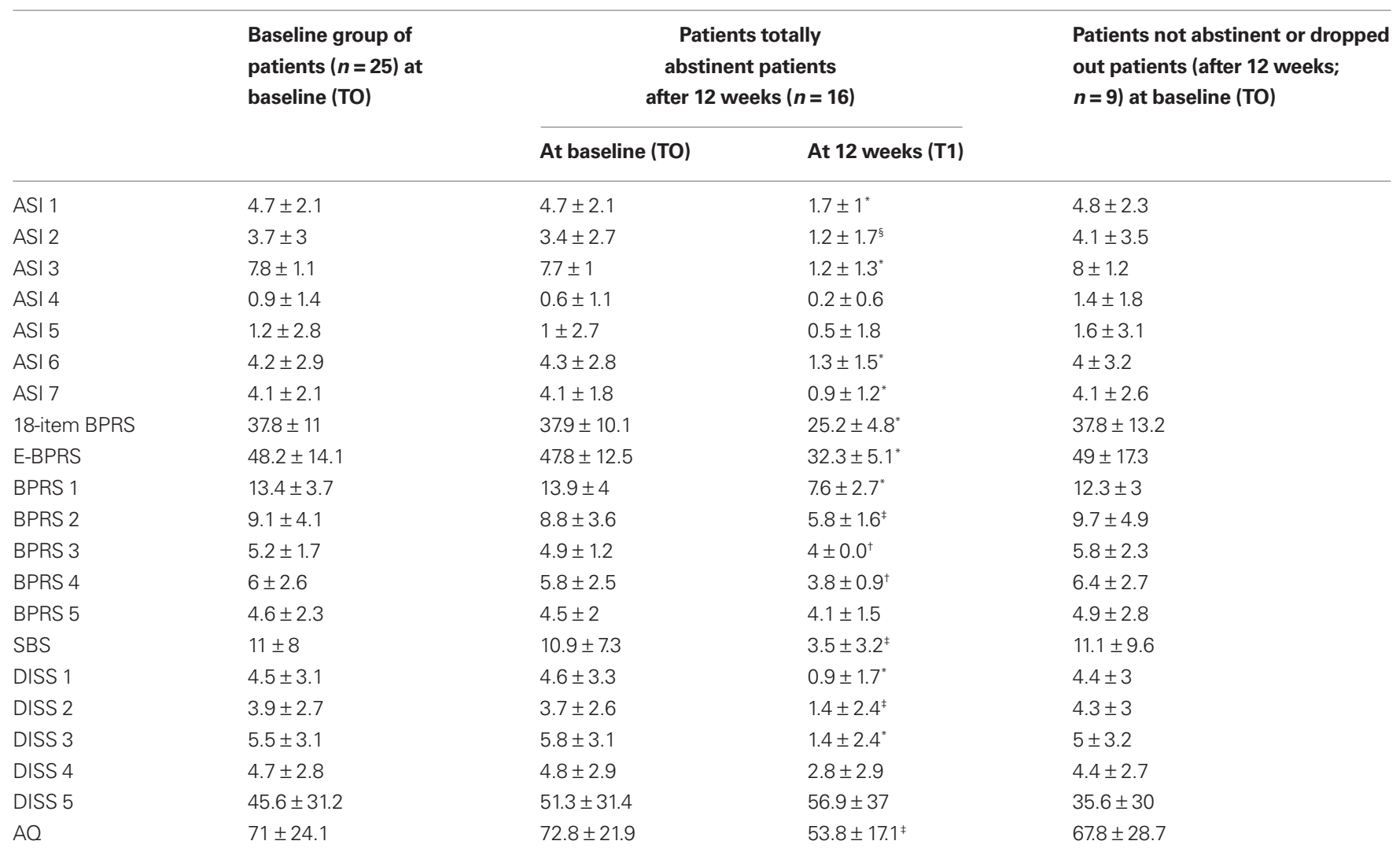

ASI, addiction severity index; BPRS, brief psychiatric rating scale; E-BPRS, expanded brief psychiatric rating scale; SBS (a), social behavior scale; DISS, Sheehan disability scale; $A Q$, aggression questionnaire. (a) SBS is in the form of the behavior severe and mild (BSM), which targets the mild and severe problems scores. ${ }^{*} p<0.0001 ;{ }^{s} p<0.005 ;{ }^{*} p<0.01 ;{ }^{+} p<0.05$ vs. the group of 16 patients at baseline.

Finally, we compared the demographic data and the psychometric assessments between those subjects totally abstinent at 12 weeks ( $n=16)$ and the rest of the subjects (those non-abstinent at 12 weeks and those dropped out; $n=9$ ). The only statistically significant difference was in the mean age. In particular, the second group $(n=9)$ had a mean age lower than those subjects totally abstinent at 12 weeks (respectively: $36.9 \pm 11.3$ versus $46.3 \pm 6.3$; $p=0.014)($ Table $\mathbf{1})$.

\section{RELATIONSHIPS BETWEEN THE PSYCHOMETRIC ASSESSMENTS AT 12-WEEK (T1)}

At T1, we found the following statistically significant correlations in the 16 subjects totally abstinent. Both BPRS and BPRS-E positively correlated with ASI 7 (respectively: $r=0.54, p=0.031 ; r=0.64$, $p=0.008$ ) and with BSM (respectively: $r=0.61, p=0.011 ; r=0.58$, $p=0.017)$. Both ASI 2 and ASI 5 positively correlated with DISS 1 (respectively: $r=0.50, p=0.049 ; r=0.61, p=0.013$ ). Both ASI 6 and ASI 7 positively correlated with DISS 2 (respectively: $r=0.58$, $p=0.017 ; r=0.66, p=0.005$ ), with DISS 3 (respectively: $r=0.58$, $p=0.017 ; r=0.66, p=0.005$ ) and with DISS 4 (respectively: $r=0.79$, $p<0.0001 ; r=0.63, p=0.009)$. A significant positive correlation was found between ASI 2 and AQ $(r=0.51, p=0.045)$. Finally, DISS 1 positively correlated with AQ $(r=0.53, p=0.034)$.

\section{DISCUSSION}

The present study indicates that several disorders, such as affective disorders, psychiatric symptoms, thinking disorders, negative symptoms, suspiciousness, hostility, aggressiveness and social, familiar, and employment disability are present in active drinking alcohol-dependent patients and that many of them have a significant improvement after a period (12 weeks) of total alcohol abstinence. To the best of our knowledge, for the first time all these psychometric assessments were simultaneously investigated in alcohol-dependent patients before and after a period of abstinence.

The present results are consistent with several studies showing that individuals with AUDs have elevated risk of psychopathology, in particular mood, anxiety and personality disorders (ModestoLowe and Kranzler, 1999; Dawson et al., 2005) as well as of severe social, familiar and employment disabilities (Room et al., 2005).

The present results showed that alcohol abstinence is able to improve several features of addiction severity, including medical (ASI 1), employment (ASI 2), alcohol (ASI 3), legal (ASI 6), and psychiatric (ASI 7) problems. Our data are consistent with the recent study of Nalpas et al. (2006), who described a significant improvement of medical, alcohol, drugs, and psychological domains and a trend of improvement for the social and familiar environment after 3 months of abstinence. 


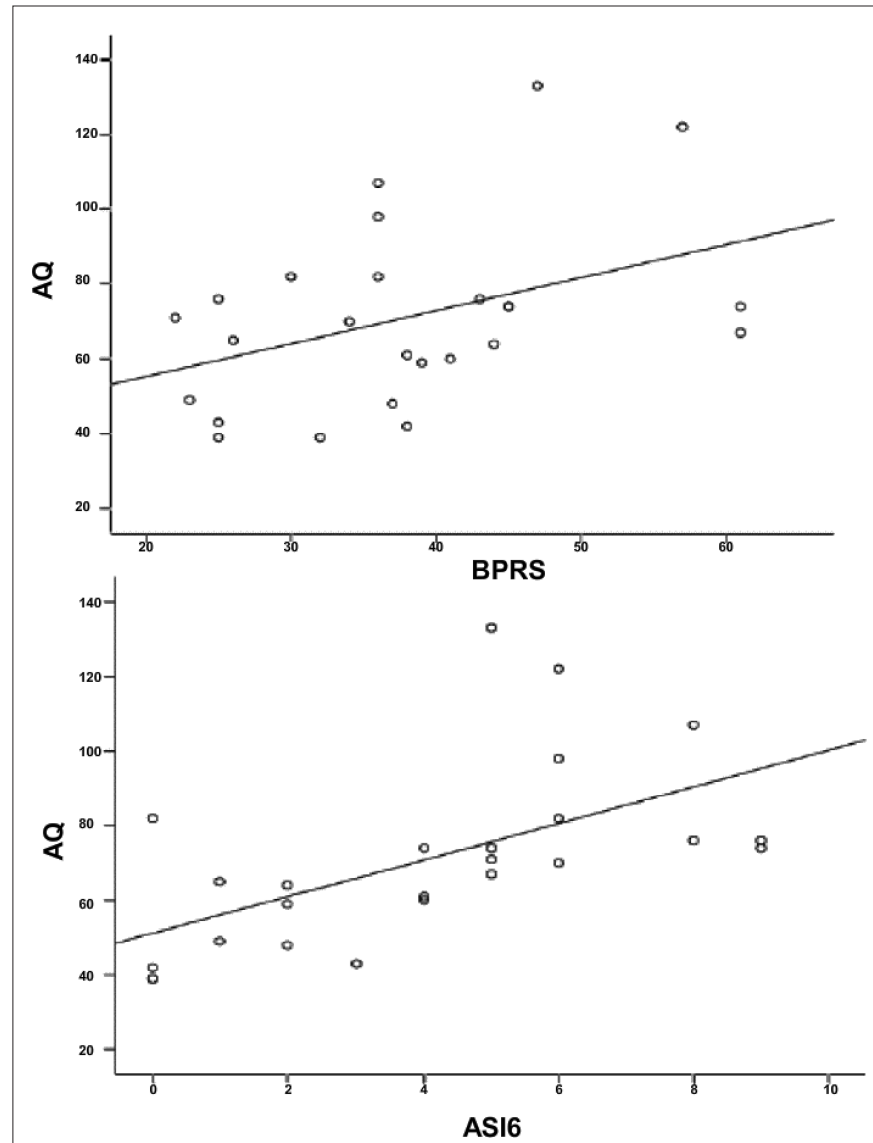

FIGURE 1 | Relationships between aggression questionnaire (AQ) and brief psychiatric rating scale (BPRS), expanded BPRS (BPRS-E), addiction severity index 6 (ASI 6), ASI 7, in the 25 alcoholic patients at baseline. Significant

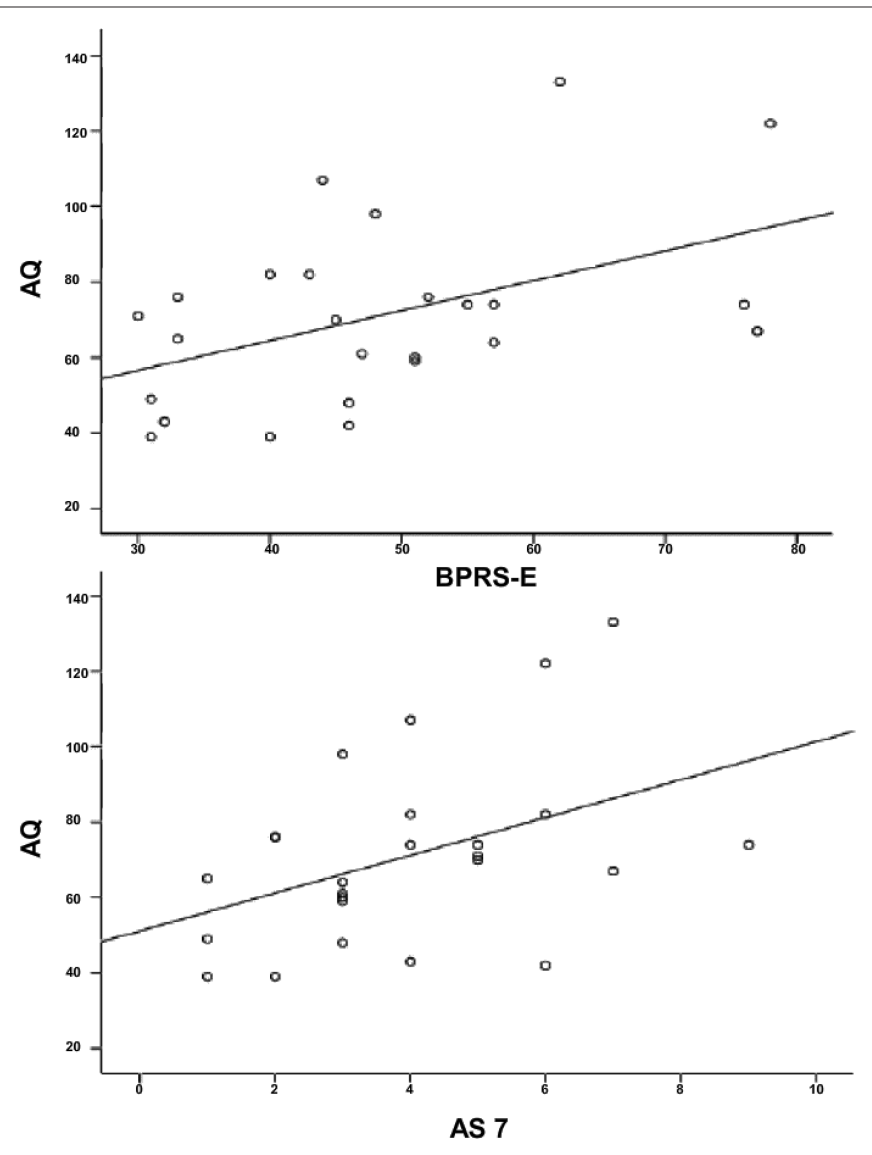

positive correlations were found between AQ and both BPRS $(r=0.46, p=0.02$; top panel) and BPRS-E ( $r=0.40, p=0.045$; top panel); $\mathrm{AQ}$ and both ASI 6 ( $r=0.58, p=0.002$; bottom panel) and ASI 7 ( $r=0.43, p=0.031$; bottom panel).
The concomitant improvement of both medical (ASI 1) and psychiatric (ASI 7) problems is consistent with the evidence that medical and psychiatric conditions are highly prevalent in alcoholics and that these conditions may benefit from alcohol abstinence (Weisner et al., 2001).

In our study, employment (ASI 2) and legal status (ASI 6) domains also improved after 12 weeks of abstinence. On the contrary, no change in the working status was found in a previous study (Slaymaker and Owen, 2006). This difference may be due to the inclusion of a significant number of unemployed participants in our study. In fact, while Slaymaker and Owen (2006) enrolled stably employed individuals who had to return to their job upon completion of the treatment, $44 \%$ of our patients were unemployed at the time of enrolment and most of them started to work achieving alcohol abstinence during our study. In our sample, the parallel improvement of other problems, such as those related to alcohol consumption helped our subjects to improve their employment status.

No changes in the ASI 4 and ASI 5 scores were found in our sample. The lack of changes in the ASI 4 (severity of consumption of other drugs) is consistent with the exclusion of patients with dual substance abuse. The ASI 5 scale (severity of social and familiar problems) was significantly reduced at 6-month follow-up and 12-month follow-up assessments in the study by Slaymaker and Owen (2006). Therefore, the lack of changes in the ASI 5 scale in our sample might be related to the brief duration of this study (12 weeks). Future studies with longer follow-ups will investigate if longer periods of abstinence improve this scale.

This study showed that alcohol abstinence is able to improve several domains of disability scale, including work (DISS 1), social life (DISS 2), family life (DISS 3). The improvement in work domain is consistent with the results already reported for ASI 2. The domains of social (DISS 2) and family life (DISS 3 ) also improved with alcohol abstinence, an observation consistent with the evidence that successful outcomes of alcohol dependence treatment include both reduction in alcohol consumption and improvement in social functioning (Simpson et al., 1997) and in familiar relationships (Maisto et al., 1998).

In the present study, no significant improvement in social and familiar support outcome (DISS 5) was found in alcoholic patients after 12 weeks of abstinence. This observation is in apparent contradiction with the improvement in social (DISS 2) and family (DISS 3 ) life. This finding could be explained by the different concepts of 

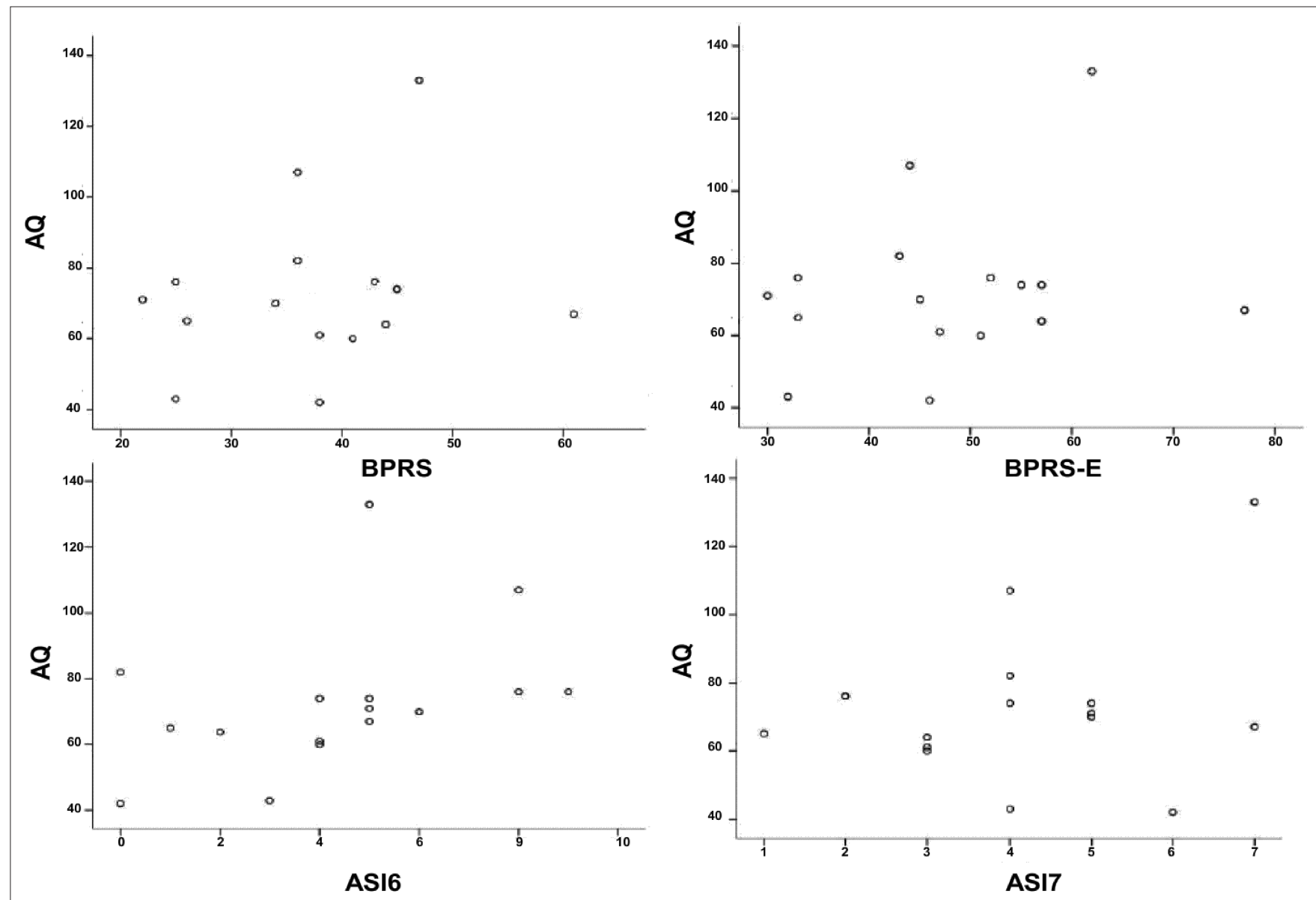

FIGURE 2 | Relationships between aggression questionnaire (AQ) and brief psychiatric rating scale (BPRS), expanded BPRS (BPRS-E), addiction severity index 6 (ASI 6), ASI 7, in the 16 alcoholic patients at baseline. No significant correlations were found between AQ and either BPRS or BPRS-E (top panel), and between $A Q$ and either ASI 6 or ASI 7 (bottom panel) $(p>0.05)$.

social compromise and social support. Social compromise ("social undermining") is a negative form of social interaction characterized by active dislike and devaluing of an individual (Gant et al., 1993) and is positively related with alcohol, drug, and mental disorders. Social support is the functional content of relationships where individuals provide aid, assistance, and comfort to others (Heaney and Israel, 2002) and is negatively related with substance abuse disorders (Beattie and Longabaugh, 1999; De La Rosa and White, 2001). Our findings are supported by recent evidence that social undermining more than social support is influenced by mental health, including substance abuse disorders (Oetzel et al., 2007).

Finally, no significant reduction of DISS 4 subscale (perception of stress) was observed. Conger (1956) suggested that alcohol consumption relieves anxiety and thus may help an individual to cope with stress. In our study, there was a reduction in anxiety after 12 weeks of abstinence according to BPRS 1 but not in the stress perception according to DISS 4 subscale. A previous study showed that problematic drinkers, followed for 1 year, improved drinking and functioning outcomes but changed less on stressors (Timko et al., 1994). It is conceivable that increased sensitivity to stress could represent a pre-existing condition to alcoholism (Sommer et al.,
2008) and persists into protracted abstinence (Hershon, 1977). Alternatively, it is possible that the DISS 4 is not able to assess changes on stressors, at least in this population, and conversely biological markers, such as adrenocorticotropic hormone (ACTH) and cortisol could be more useful (Munro et al., 2005; Leggio et al., 2008b). In agreement with previous studies (Rubio et al., 2006; Martinotti et al., 2008), our data showed that alcohol abstinence improves total scores of BPRS (BPRS and BPRS-E). Moreover, in our sample several psychopathological domains, such as affective, mood and anxiety-related disorders (BPRS 1), negative symptoms (BPRS 2), psychotic and thinking disorders (BPRS 3), activation symptoms (BPRS 4) showed a significant improvement. As we expected, we found an improvement in affective, mood and anxietyrelated disorders (BPRS 1), supporting the hypothesis that these symptoms could be a consequence of alcohol dependence (Schuckit, 2006). BPRS 2 domain (negative symptoms) also improved in our abstinent alcoholic patients, supporting the evidence that alcoholic patients develop a proceeding neglect of important interests and habits with an improvement of these symptoms after a period of abstinence (de Greck et al., 2008). We also found an improvement in psychotic and thinking disorders (BPRS 3), even if patients with 
psychosis were not enrolled. This aspect could be justified by the observation that some symptoms in alcoholics may mimic psychiatric pictures (Schuckit, 2006). The employment of psychometric tests to evaluate these substance-induced symptoms could represent an important tool to better understand the complex relationship between psychiatric and substance-related disorders. Finally, the improvement of activation symptoms (BPRS 4; i.e.: excitement, tension, motor hyperactivity, distractibility) is consistent with the parallel improvement of other assessments, such as anxiety evaluated by BPRS 1, aggression evaluated by AQ and psychiatric problems evaluated by ASI 7.

The lack of changes in suspiciousness and hostility symptoms (BPRS 5) is consistent with the evidence that suspiciousness and hostility create a predisposition to the development of alcoholism (Gottschalk et al., 1983). Notably, a recent study reported that after a 3-year abstinence period, socially well-adapted recovered alcoholics still displayed signs of hostility (Ziherl et al., 2007).

In this study, while hostility did not improve in alcoholic patients after 12 weeks of abstinence, a significant improvement of aggressive behavior was found. Besides the prolonged alcohol abstinence, the psychological support counseling provided also played a role. Psychosocial treatment is an essential component of any treatment program for substance misuse disorders (American Psychiatric Association, 1995; Dutra et al., 2008).

In this study, we found several significant correlations between the different psychometric assessments used both before and after total alcohol abstinence. This observation could be related to the fact that some assessments (i.e., BPRS, ASI, DISS, BSM) partially address similar psychometric features, therefore resulting in a possible overlap. On the other hand, these results also confirm the utility of using assessments with different structures (i.e., self-reported assessments as the DISS versus semi-structured interviews like BPRS, ASI, and BSM) to investigate specific psychometric aspects.

At T0, when we analyzed separately the subgroup of 16 patients (those totally abstinent at the end of the study), we found that the correlations between AQ and other scales (total BPRS scores, ASI 6 and ASI 7) were not present anymore as in the whole sample of 25 patients (see also Figures 1 and 2 ). This observation might lead to speculate that subjects with an important aggressive behavior are less likely to be totally abstinent during the treatment program. There is a well-recognized association between AUDs and aggressive behavior (Ziherl et al., 2007). For example, it is known that same genetic factors may be linked to both alcohol dependence and aggressive behavior (Von der Pahlen et al., 2008) and the presence of an aggressive behavior represents a marker of more severe alcohol dependence (Mann et al., 1998; Leggio and Addolorato, 2008). Consistent with these hypotheses, in our sample the presence of a correlation between aggressive behavior and other psychosocial symptoms was a characteristic discerning those subjects totally abstinent at the end of the study versus those non-abstinent.

\section{REFERENCES}

Addolorato, G., Caputo, F., Capristo, E., Domenicali, M., Bernardi, M., Janiri, L., Agabio, R., Colombo, G., Gessa, G. L., and Gasbarrini, G. (2002). Baclofen efficacy in reducing alcohol craving and intake: a preliminary double-blind randomized controlled study. Alcohol Alcohol. 37, 504-508.

Addolorato, G., Leggio, L., Ferrulli, A., Cardone, S., Vonghia, L., Mirijello, A., Abenavoli L, D’Angelo, C., Caputo, F., Zambon, A., Haber, P. S., and Gasbarrini, G. (2007). Effectiveness

Notably, aggressive behavior usually characterizes subjects with an early onset of alcoholism (Träskman-Bendz and Westling, 2005). Although the small sample did not allow us to classify subjects according to different typologies (i.e., early and late onset, Cloninger typologies, Babor typologies; see Leggio et al., 2009), when we compared those subjects totally abstinent after 12 week and the other nine subjects (those non-abstinent at 12 weeks and those dropped out), we found that the only statistically significant difference was the presence of a lower mean age in the second group. All together, these results suggest that aggressive trait and younger age might play a role in the subgroup of subjects that were not able to conclude the study and/or were not able to maintain total alcohol abstinence during the study.

At T1, when we analyzed the group of 16 patients, we found that total BPRS scales still correlated with ASI 7, but not with ASI 3, AQ, DISS subscales. Moreover, several correlations between DISS and ASI disappeared. This observation is probably related to the fact that total alcohol abstinence allowed a significant improvement of most of the assessments scores. The presence of low scores ("floor effect") might also contribute to the lack of correlations at $\mathrm{T} 1$.

This study has limitations that must be addressed. First, the low number of patients enrolled limits the interpretability of the results. Second, no control group was included in this research. In fact, the disappearance of some of the correlations between the psychometric assessments could be related to the use of the GABAergic baclofen as anti-craving medication. For example, Krupitsky et al. (1993) showed that baclofen was able to ameliorate affective disturbances such as anxious and depressive disorders in alcoholics. Addolorato et al. (2002) and Flannery et al. (2004) found that baclofen-treated alcoholics presented an improvement of anxiety but not depressive mood. It may be hypothesized that the decrease of psychological symptoms such as anxiety in alcoholics after a period of abstinence could be secondary to the administration of baclofen (Addolorato et al., 2002). Therefore, future studies will have to investigate the psychometric assessments used in the present study using a placebo-controlled study to investigate if the improvement of these psychometric assessments was related to the achieving of total alcohol abstinence, to the use of a medication such as baclofen, or to both factors.

Despite these limitations, this study firstly investigated simultaneously several affective disorders and psychosocial problems, such as aggression, impulsivity, negative symptoms, activation problems solving, social interaction in alcohol-dependent patients, demonstrating their improvement after a period of total alcohol abstinence.

\section{ACKNOWLEDGMENTS}

The present study was partially supported by a grant from the European Foundation for Alcohol Research (ERAB) and partially by a grant from the Catholic University of Rome (D1-2008).

and safety of baclofen for maintenance of alcohol abstinence in alcoholdependent patients with liver cirrhosis: randomised, double-blind controlled study. Lancet 370, 1915-1922.

Alterman, A. I., Kushner, H., and Holahan, J. M. (1990).Cognitive functioning and treatment outcome in alcoholics. J. Nerv. Ment. Dis. 178, 494-499.

American Psychiatric Association. (1994). Diagnostic and statistical manual of mental disorders, 4 th edn. Washington, DC: American Psychiatric Association. 
American Psychiatric Association. (1995). Practical guidelines for the treatment of patients with substance use disorders: alcohol, cocaine, opioids. Am. J. Psychiatry 152, 5-59.

Bácskai, E., Czobor, P., and Gerevich, J. (2009). Suicidality and trait aggression related to childhood victimization in patients with alcoholism. Psychiatry Res. 165, 103-110.

Batki, S. L., Dimmock, J. A., Wade, M., Gately, P. W., Cornell, M., Maisto, S. A., Carey, K. B., and Ploutz-Snyder, R. (2007).Monitored naltrexone without counselling for alcohol abuse/dependence in schizophrenia-spectrum. Am. J. Addict. 16, 253-259.

Beattie, M., and Longabaugh, R. (1999). General and alcohol-specific social support following treatment. Addict. Behav. 24, 593-606.

Bokij, I. V. (1983). "Affective disorders in alcoholics and their therapy," in Affective Disturbances in Alcoholism, ed. I. V. Bokij (Leningrad: Leningrad Research Psycho-Neurological Institute), 5-9.

Buss, A. H., and Perry, M. (1992). The aggression questionnaire. J. Pers. Soc. Psychol. 63, 452-459.

Carpiniello, B., Baita, A., Carta, M. G., Sitzia, R., Macciardi, A. M., Murgia, S. and Altamura, A. C. (2002). Clinical and psychosocial outcome of patients affected by panic disorder with or without agoraphobia: results from a naturalistic follow-up study. Eur. Psychiatry 17, 394-398.

Conger, J. J. (1956). Alcoholism: theory, problem and challenge, II: reinforcement theory and the dynamics of alcoholism. Q. J. Stud. Alcohol 17, 296-305.

Dawson, D. A., Grant, B. F., Stinson, F. S., and Chou,P.S.(2005).Psychopathology associated with drinking and alcohol use disorders in the college and general adult populations. Drug Alcohol Depend. 77, 139-150.

de Greck, M., Supady, A., Thiemann, R., Tempelmann, C., Bogerts, B., Forschner, L., Ploetz, K. V., and Northoff, G. (2008). Decreased neural activity in reward circuitry during personal reference in abstinent alcoholics-A fMRI study. Hum. Brain Mapp. 30, 1691-1704.

De La Rosa, M. R., and White, M. S. (2001). A review of the role of social support systems in the drug use behavior of Hispanics. J. Psychoactive Drugs 33, 233-240.

Dom, G., D'haene, P., Hulstijn, W., and Sabbe, B. (2006). Impulsivity in abstinent early- and late-onset alcoholics: differences in self-report measures and a discounting task. Addiction 101, 50-59.
Driessen, M., Schulte, S., Luedecke, C. Schaefer, I., Sutmann, F., Ohlmeier, M. Kemper, U., Koesters, G., Chodzinski, C., Schneider, U., Broese, T., Dette, C., Havemann-Reinicke, U., and TRAUMAB Study Group. (2008). Trauma and PTSD in patients with alcohol, drug, or dual dependence: a multi-center study. Alcohol. Clin. Exp. Res. 32, 481-488.

Dritschel, B. H., and Pettinati, H. M. (1989). The role of female occupation in severity of alcohol-related problems. Am. J. Drug Alcohol Abuse 15, 61-72.

Dutra, L., Stathopoulou, G., Basden, S. L., Leyro, T. M., Powers, M. B., and Otto, M. W. (2008). A meta-analytic review of psychosocial interventions for substance use disorders. Am. J. Psychiatry 165, 179-187.

Flannery, B. A., Garbutt, J. C., Cody, M. W., Renn, W., Grace, K., Osborne, M., Crosby, K., Morreale, M., and Trivette, A. (2004). Baclofen for alcohol dependence: a preliminary openlabel study. Alcohol Clin. Exp. Res. 28, 1517-1523.

Gant, L. M., Nagda, B. A., Brabson, H. V., Jayaratne, S., Chess, W. A., and Singh, A. (1993). Effects of social support and undermining on African American workers' perceptions of coworker and supervisor relationships and psychological well-being. Soc. Work 38, 158-164.

Gerevich, J., Bácskai, E., and Czobor, P. (2007). Aggression levels in treatment seeking inpatients with alcohol-related problems compared to levels in the general population in Hungary. $J$. Nerv. Ment. Dis. 195, 669-672.

Giancola, P. R. (2002). Irritability, acute alcohol consumption and aggressive behavior in men and women. Drug Alcohol Depend. 68, 263-274.

Gottschalk, L. A., Hoigaard-Martin, J. C., Eckardt, M. J., Gilbert, R. L., and Wolf, R. J. (1983). Cognitive impairment and other psychological scores derived from the content analysis of speech in detoxified male chronic alcoholics. Am. J. Drug Alcohol Abuse 9, 447-460.

Hamid, W. A., Wykes, T., and Stansfeld, S. (1995). The social disablement of men in hostels for homeless people. I. Reliability and prevalence. $\mathrm{Br}$. $\mathrm{J}$. Psychiatry 166, 806-808.

Heaney, C. A., and Israel, B. A. (2002) "Social networks and social support," in Health Behavior and Health Education: Theory, Research, and Practice, eds K. Glanz, B. K. Rimer and F. M. Lewis (San Francisco: John Wiley), 185-209.

Hershon, H.I. (1977). Alcohol withdrawal symptoms and drinking behavior. $J$. Stud. Alcohol 38, 953-971.
Hodgins, D. C., and el-Guebaly, N. (1992). More data on the addiction severity index. Reliability and validity with the mentally ill substance abuser. J. Nerv. Ment. Dis. 180, 197-201.

Kranzler, H. R. (1996). Evaluation and treatment of anxiety symptoms and disorders in alcoholics. J. Clin. Psychiatry 7, 15-21.

Kranzler, H. R., Mason, B., and ModestoLowe, V. (1998). "Prevalence, diagnosis, and treatment of comorbid mood disorders and alcoholism," in Dual Diagnosis and Treatment, eds $\mathrm{H}$. R. Kranzler and B. Rounsaville (New York: Marcel Dekker), 107-136.

Krupitsky, E. M., Burakov, A. M., Ivanov, V. B., Krandashova, G. F., Lapin, I. P. Ja Grinenko, A., and Borodkin, Yu. S. (1993). Baclofen administration for the treatment of affective disorders in alcoholic patients. Drug Alcohol Dep. 33, 157-163

Langeland, W., Draijer, N., and van den Brink, W. (2003). Assessment of lifetime physical and sexual abuse in treated alcoholics. Validity of the addiction severity index. Addict. Behav. 28, 871-881.

Leggio, L., and Addolorato, G. (2008) The serotonin transporter (SERT) brain density and the neurobiological Cloninger subtypes model: a lesson by human autoradiography studies. Alcohol Alcohol. 43, 148-150.

Leggio, L., Ferrulli, A., Cardone, S. Miceli, A., Kenna, G. A., Gasbarrini, G., Swift, R. M., and Addolorato, G. (2008a). Renin and aldosterone but not the natriuretic peptide correlate with obsessive craving in mediumterm abstinent alcohol-dependent patients: a longitudinal study. Alcohol 42, 375-381.

Leggio, L., Ferrulli, A., Cardone, S. Malandrino, N., Mirijello, A. D’Angelo, C., Vonghia, L., Miceli, A., Capristo, E., Kenna, G. A., Gasbarrini, G., Swift, R. M., and Addolorato, G. (2008b). Relationship between the hypothalamic-pituitary-thyroid axis and alcohol craving in alcoholdependent patients: a longitudinal study. Alcohol. Clin. Exp. Res. 32, 2047-2053.

Leggio, L., Kenna, G. A., Fenton, M. Bonenfant, E., and Swift, R. M. (2009) Typologies of alcohol dependence. From Jellinek to genetics and beyond. Neuropsychol. Rev. 19, 115-129.

Maisto, S. A., McKay, J. R., and O'Farrell, T. J. (1998). Twelve-month abstinence from alcohol and long-term drinking and marital outcomes in men with severe alcohol problems. J. Stud. Alcohol 59, 591-598.

Mann, K., Ackermann, K., Jung, M. Morlock, P., and Mundle, G. (1998)
Aggressiveness, onset of dependence, and treatment outcome in socially well-adapted alcoholics. Alcohol Alcohol. 33, 161-169.

Marshall, E. J., and Alam, F. (1997). Psychiatric problems associated with alcohol misuse and dependence. Br.J. Hosp. Med. 58, 44-46.

Martinotti, G., Andreoli, S., Di Nicola, M., Di Giannantonio, M., Sarchiapone, M., and Janiri, L. (2008). Quetiapine decreases alcohol consumption, craving, and psychiatric symptoms in dually diagnosed alcoholics. Hum. Psychopharmacol. 23, 417-424.

Mayfield,D.M., and Coleman,L.L.(1968). Alcohol use and affective disorder. Dis. Nerv. Syst. 29, 467-474.

McLellan,A. T., Luborsky, L., Woody, G. E., and O'Brien, C.P.(1980). An improved diagnostic evaluation instrument for substance abuse patients: the addiction severity index. J. Nerv. Mental Dis. $168,26-33$.

Miller, F., Barasch, A., Sacks, M., Levitan, J., and Ashcroft, L. (1986). Serum prolactin correlated with depressed mood during alcohol withdrawal. Drug Alcohol Depend. 17, 331-338.

Modesto-Lowe, V., and Kranzler, H. R. (1999). Diagnosis and treatment of alcohol-dependent patients with comorbid psychiatric disorders. Alcohol Res. Health 23, 144-149.

Munro, C.A., Oswald, L. M., Weerts, E. M., McCaul, M.E., and Wand, G. S. (2005). Hormone responses to social stress in abstinent alcohol-dependent subjects and social drinkers with no history of alcohol dependence. Alcohol. Clin. Exp. Res. 29, 1133-1138.

Nalpas, B., Matelak, F., Martin, S., Boulze I., Balmes, J. L., and Crouzet, C. (2006). Clinical management methods for out-patients with alcohol dependence. Subst. Abuse Treat. Prev. Policy 1, 5.

Oetzel, J., Duran, B., Jiang, Y., and Lucero, J. (2007). Social support and social undermining as correlates for alcohol, drug, and mental disorders in American Indian women presenting for primary care at an Indian Health Service hospital. J. Health Commun. 12, 187-206.

Overall, J. E., and Gorham, D. R. (1962). The brief psychiatric rating scale. Psychol. Rep. 10, 790-812.

Room, R., Babor, T., and Rehm, J. (2005). Alcohol and public health. Lancet 365 , 519-530.

Ross, H. E., Glaser, F. B., and Germanson, T. (1988). The prevalence of psychiatric disorders in patients with alcohol and other drug related problems. Arch. Gen. Psychiatry 47, 1023-1031.

Rubio, G., López-Muñoz, F., and Alamo, C. (2006). Effects of lamotrigine in patients with bipolar disorder and 
alcohol dependence. Bipolar Disord. 8, 289-293.

Schuckit, M. A. (2006). Comorbidity between substance use disorders and psychiatric conditions. Addiction 101(Suppl. 1), 76-88.

Schuckit, M. A., and Monteiro, M. G. (1988). Alcoholism, anxiety and depression. Br. J. Addict. 83, 1373-1380.

Sheehan, D. V., Harnett-Sheehan, K., and Raj, B. A. (1996). The measurement of disability. Int. Clin. Psychopharmacol. 11(Suppl. 3), 89-95.

Simpson, D. D., Joe, G. W., and Brown, B. S. (1997). Treatment retention and follow-up outcomes in the drug abuse treatment outcome study (DATOS). Psychol. Addict. Behav. 11, 294-301.

Slaymaker, V. J., and Owen, P. L. (2006). Employed men and women substance abusers: job troubles and treatment outcomes. J. Subst. Abuse Treat. 31, 347-354.

Sommer, W. H., Rimondini, R., Hansson, A. C., Hipskind, P. A., Gehlert, D. R., Barr, C. S., and Heilig, M. A. (2008).
Upregulation of voluntary alcohol intake, behavioral sensitivity to stress, and amygdala crhrl expression following a history of dependence. Biol. Psychiatry 63, 139-145.

Stockwell, T., and Bolderston, H. (1987). Alcohol and phobias. Br. J. Addict. 82, 971-979.

Timko, C., Moos, R. H., Finney, J. W., and Moos, B. S. (1994). Outcome of treatment for alcohol abuse and involvement in alcoholics anonymous among previously untreated problem drinkers. J. Ment. Health Adm. 21, 145-160.

Träskman-Bendz, L., and Westling, S. (2005). The psychobiology of aggressive behaviour. Adv. Health Econ. Health Serv. Res. 16, 3-14.

Troisi, A., Pompili, E., Binello, L., and Sterpone, A. (2007). Facial expressivity during the clinical interview as a predictor functional disability in schizophrenia. a pilot study. Prog. Neuropsychopharmacol.Biol. Psychiatry $31,475-481$.

Ventura, J., Lukoff, D., Nuechterlein, K. H., Liberman, R. P., Green, M. F., and Shaner, A. (1993). Manual for the expanded brief psychiatric rating scale. Intern. J. Meth. Psych. Res. 3, 227-244.

Von der Pahlen, B., Santtila, P., Johansson, A., Varjonen, M., Jern, P., Witting, K., and Kenneth Sandnabba, N. (2008). Do the same genetic and environmental effects underlie the covariation of alcohol dependence, smoking, and aggressive behaviour? Biol. Psychol. 78, 269-277.

Weisner, C., Mertens, J., Parthasarathy, S., Moore, C., and Lu, Y. (2001). Integrating primary medical care with addiction treatment: a randomized controlled trial. JAMA 286, 1715-1723.

Wykes, T., and Sturt, E. (1986). The measurement of social behaviour in psychiatric patients: an assessment of the reliability and validity of the SBS schedule. Br. J. Psychiatry 148, 1-11.

Ziherl, S., Cebasek Travnik, Z., Kores Plesnicar, B., Tomori, M., and Zalar, B. (2007). Trait aggression and hostility in recovered alcoholics. Eur. Addict. Res. 13, 89-93.
Conflict of Interest Statement: The authors declare that the research was conducted in the absence of any commercial or financial relationships that could be construed as a potential conflict of interest.

Received: 16 February 2010; paper pending published: 06 March 2010; accepted:01 June 2010; published online: 06 July 2010. Citation: Ferrulli A, Leggio L, Cardone S, D'Angelo C, Mirijello A, Vonghia L, Miceli A, Gasbarrini $G$ and Addolorato G (2010) Psychosocial findings in alcohol-dependent patients before and after three months of total alcohol abstinence. Front. Psychiatry 1:17. doi: 10.3389/fpsyt.2010.00017

This article was submitted to Frontiers in Addictive Disorders, a specialty of Frontiers in Psychiatry.

Copyright $\odot 2010$ Ferrulli, Leggio, Cardone, D’Angelo, Mirijello, Vonghia, Miceli, Gasbarrini and Addolorato. This is an open-access article subject to an exclusive license agreement between the authors and the Frontiers Research Foundation, which permits unrestricted use, distribution, and reproduction in any medium, provided the original authors and source are credited. 